$\begin{array}{cc}\text { ACADEMIA ROMÂNĂ } & \text { Rev. Roum. Chim., } \\ \text { 2020, 65(5), 499-508 }\end{array}$

\title{
REMOVAL PROPERTIES OF METHYLENE BLUE FROM AQUEOUS SOLUTIONS BY ORGANOMODIFIED MONTMORILLONITE: ISOTHERM, THERMODYNAMICS AND KINETIC STUDIES
}

\author{
Soufiane BOUDJEMAA ${ }^{\mathrm{a}, \mathrm{b},{ }^{*}}$ and Belkacem ZIDELKHEIR ${ }^{\mathrm{c}}$ \\ ${ }^{a}$ Laboratory of Chemical Process Engineering, Ferhat Abbas setif 1 University, Algeria \\ ${ }^{\mathrm{b}}$ Faculty of Sciences and Technology, Mohamed El Bachir El Ibrahimi B.B.A University, Algeria \\ ${ }^{\mathrm{c}}$ Chemical Engineering Department, Mohamed Boudiaf M'sila University, Algeria
}

Adsorption of Methylene Blue (MB) from water via batch adsorption experiments onto montmorillonite (MMT) and organomodified montmorillonite (OMMT) was investigated. The organomodified montmorillonite was synthesized by montmorillonite and n-hexadecyltrimethylammonium chloride. The organomodified montmorillonite was characterized by FT-IR, XRD, ATG, SEM, and Nitrogen adsorption measurements (BET). Studie concerning the factors influencing the adsorption capacitie of montmorillonite and organomodified montmorillonite, such as the contact time, adsorbent dosage, initial dye concentration, $\mathrm{pH}$,

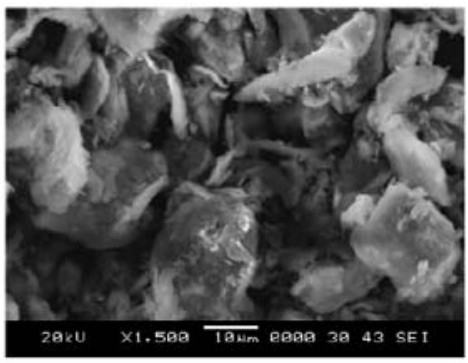

(a)

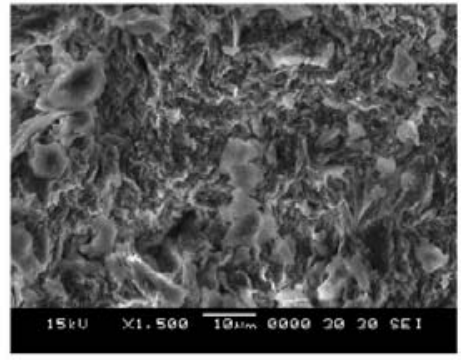

(b) and temperature were systematically investigated and discussed. The experimental results show that the percentage of dye removal increases with the increasing the amount of sorbent. Adsorption was $\mathrm{pH}$ dependent. The results revealed that organomodified montmorillonite demonstrated high adsorption capacities toward basic dyes, while montmorillonite exhibited sorption capacities lower than organomodified montmorillonite.The equilibrium data were fitted to Langmuir and Freundlich isotherms and the equilibrium adsorption was best described by the Langmuir isotherm model. The kinetics data were analyzed using pseudo-first and pseudo-second-order models. It was best described by the pseudo-second-order model. Thermodynamic parameters $\Delta \mathrm{G}^{\circ}, \Delta \mathrm{H}^{\circ}$ and $\Delta \mathrm{S}^{\circ}$ were calculated for the adsorption of Methylene Blue on montmorillonite and organomodified montmorillonite; the value of $\Delta \mathrm{G}^{\circ}$ showed the spontaneous nature of adsorption for both sorbents and the process was endothermic.

\section{INTRODUCTION}

Dyes are more stable due to their artificial origin and their complex molecular structure, they are not easily biodegraded and conventional water treatment methods are proven to be ineffective. ${ }^{1}$ Synthetic dyes can be found in the wastewater from various industries like paper, leather, plastics and textiles. ${ }^{2}$ Wastewater discharges into rivers and natural streams from the industries that use dyes poses stark environmental problems. When these dyes are introduced into surface waters, it limits sunlight transmission into the water due to its colour intensity. This has a negative effect on aquatic plants and therefore it is hazardous to the aquatic ecosystem. ${ }^{3,4}$ Furthermore, many of dyes are toxic or carcinogenic.$^{5}$ Hence, the elimination of dyes from wastewater accepted environmental importance. Many approaches have been developed for decontamination of water, e.g. precipitation, electrodialysis, adsorption, filtration, coagulation, oxidation and membrane separation. ${ }^{6}$

\footnotetext{
*Corresponding authors: bsouf77@yahoo.fr
} 
However, adsorption is known to be one of the most effective techniques to eliminate dyes from water. Activated carbon has been familiarized as adsorbent due to its great sorption capacity for the dyes. ${ }^{7}$ However the high cost has led us seeking for low-cost sorbents. Recently, low-cost materials such as fly ash ${ }^{8}$, natural zeolite ${ }^{9}$, redmud ${ }^{10}$ and coir pith $^{11}$ accepted vital interest for wastewater treatment. Several modified montmorillonite are also reported to be inexpensive and effective in water decontamination. ${ }^{12,13}$

Montmorrllonite is a 2:1 type of mineral, comprises of one octahedral alumina sheet lying between two tetrahedral layers of silica. The permanent negative charge of montmorrllonite is attributed to the isomorphous replacement of $\mathrm{Al}^{3+}$ for $\mathrm{Si}^{4+}$ in the tetrahedral layer and $\mathrm{Mg}^{2+}$ for $\mathrm{Al}^{3+}$ in the octahedral layer. This negative charge is balanced by the presence of replaceable cations $\left(\mathrm{Ca}^{2+}, \mathrm{Na}^{+}\right.$, etc. $)$in the lattice structure, which enhance adsorbing cationic pollutants. ${ }^{14,15}$ Although, montmorrllonite weakly adsorbs acidic contaminants due to repulsion force between the anion and the negative charge on the surface of the montmorillonite. ${ }^{16,17}$ Several authors have informed the use of montmorillonite modified and organomontmorillonite with a cationic surfactant for acidic dye elimination via high loading quantity of surfactant. ${ }^{18,19}$ Basically, the modification reactions are accomplished by replacing the inter layer cations (e.g. $\mathrm{Na}^{+}, \mathrm{K}^{+}, \mathrm{Ca}^{2+}$ ) with specific species to alter the surface and structural characteristics of the clay. Hence organo clays are powerful adsorbents for a wide variety of environmental applications. ${ }^{19,20}$ The surface properties of montmorillonite can be greatly modified with a surfactant by simple ion-exchange reactions. This is favoured by Vanderwaals interaction between organic surfactant cations and the reduced solvent shielding of the ions in the interamolecular environment. Large organic cations (cationic surfactants) of the form $\left(\mathrm{CH}_{3}\right)_{3} \mathrm{~N}^{+} \mathrm{R}$ (where $\mathrm{R}$ is an alkyl hydrocarbon) occupy the exchange sites of the bentonite clay and hence the surface area is increased. ${ }^{21}$

In the present study, montmorillonite was modified by $n$-hexadecyl trimethyl ammonium chloride resulting in a new adsorbent, organomodified montmorillonite, to improve the sorption capacity for basic contaminants. montmorillonite and organomodified montmorillonite were characterized by X-ray diffraction, infrared spectrophotometery, thermal gravimetric analysis, scanning electron microscopy, and Nitrogen adsorption measurements (BET). The capacity of adsorption for the removal Methylene Blue was estimated. The influences of $\mathrm{pH}$, the contact time, adsorbent dosage, initial dye concentration, temperature, and equilibrium time on the adsorption were also investigated in batch methods. Also, in order to evaluate the adsorption process we used the first- and second- order sorption kinetics model. The Langmuir and Freundlich isotherms were investigated.

\section{EXPERIMENTAL}

\section{Materials}

Ruffi an montmorillonite (MMT) with cationic exchange capacity of $95 \mathrm{meq} / 100 \mathrm{~g}$ was supplied by the County of Maghnia, Algeria, and used after purification. $n$-Hexadecyl Trimethyl Ammonium Chloride (HTACl) as organomodification was obtained from Alfa Aesar. Methylene Blue (MB) \{3, 9-bis dimethyl- aminophenazo thionium chloride\}, was obtained from Merck and was used without further purification. The dye has molecular formula $\mathrm{C}_{16} \mathrm{H}_{18} \mathrm{ClN}_{3} \mathrm{~S}$ and molecular weight $319.85 \mathrm{~g} / \mathrm{mol}$. The standard dye solution of $1.000 \mathrm{mg} . \mathrm{L}^{-1}$ was prepared as stock solution and subsequently, whenever necessary, diluted. The structure of this dye is shown in Fig. 1.<smiles>CN(C)c1ccc2nc3ccc(N(C)C)cc3[s+]c2c1</smiles>

Fig. 1 - The structure of Methylene Blue.

\section{Organomontmorillonite (OMMT) preparation}

The OMMT was prepared by cation exchange reaction between the cation of the MMT and modifying agent (HTACl). Typically, $100 \mathrm{~g}$ of MMT was suspended into $600 \mathrm{ml}$ distilled water and stirred for $1 \mathrm{~h}$ at $75^{\circ} \mathrm{C}$. Then clay suspensions were dropwise slowly added into the modifying agent $\left(34.4 \mathrm{~g} \mathrm{HTACl}+200 \mathrm{ml}\right.$ distilled at $\left.75^{\circ} \mathrm{C}\right)$, the mixture was stirred vigorously for $2 \mathrm{~h}$ at $75^{\circ} \mathrm{C}$. The OMMT was separated by centrifugation (4000rpm, $7 \mathrm{~min}$ ). after, that, the precipitate was collected on a filter paper, washed three times with distilled water at $65^{\circ} \mathrm{C}$ under the control of $\mathrm{AgNO}_{3}$. The precipitate was dried to obtain a modified montmorillonite with $\mathrm{HTACl}$ (OMMT).

\section{Adsorption Studies}

In order to study the effects of different parameters such as the contact time, $\mathrm{pH}$, sorbent dosage, and initial dye concentration on sorption, various experiments have been carried out by agitation of known amounts of OMMT $(0.1 \mathrm{~g})$ in $50 \mathrm{~mL}$ of dye solution with an initial concentration of $100 \mathrm{mg} \cdot \mathrm{L}^{-1}$ on a rotary shaker at a constant speed of $150 \mathrm{rpm}$ at room temperature $\left(25^{\circ} \mathrm{C}\right)$. Samples were withdrawn at appropriate time intervals and centrifuged at $3000 \mathrm{rpm}$ for $5 \mathrm{~min}$, and the absorbance of the supernatant was measured using a UV-vis spectrophotometer at maximum absorbance $(\lambda \max )$ of dye. The effect of $\mathrm{pH}$ was studied by adjusting the $\mathrm{pH}$ of the dye solutions in the range of 2-12 with $0.1 \mathrm{~N} \mathrm{NaOH}$ or $\mathrm{HCl}$ solutions. To evaluate the adsorption thermodynamic 
parameters, the effects of temperature on adsorption were carried out at $20-60^{\circ} \mathrm{C}$. Kinetics of adsorption were determined by analyzing sorbate uptake of the dye from aqueous solution at different time intervals. For sorption isotherm determination, dye solutions of different concentrations were agitated with known amounts of sorbents until the equilibrium was achieved at room temperature $\left(25^{\circ} \mathrm{C}\right)$. The amount of $\mathrm{MB}$ adsorbed by sorbent \% adsorption was calculated by the following mass balance relationship:

$$
\% \text { Adsorbtion }=\left(\frac{C_{0}-C}{C_{0}}\right) \times 100
$$

The amount of adsorbed MB at any time, $\mathrm{q}_{\mathrm{t}}(\mathrm{mg} / \mathrm{g})$, by MMT and OMMT can be calculated from the mass balance expression:

$$
q_{t}=\frac{\left(C_{0}-C_{t}\right)}{m} \times V
$$

where $\mathrm{q}_{\mathrm{t}}(\mathrm{mg} / \mathrm{g})$ is the amount of MB adsorbed at time $\mathrm{t}, \mathbf{C}_{\mathbf{0}}$ and $\mathbf{C}_{\mathbf{t}}$ are, respectively, the initial concentration and concentration at time $\mathrm{t}(\mathrm{mg} / \mathrm{L}), \mathrm{V}$ the volume of solution (L), and $\mathrm{m}$ the weight of adsorbent used $(\mathrm{g})$.

\section{Characterization}

FTIR spectrum of MMT and OMMT were achieved by Fourier Spectrophotometer Spectrum type Shimadzu FTIR-8300 one in the range of $400-4000 \mathrm{~cm}^{-1}$, using $\mathrm{KBr}$ disc method.

$\mathrm{X}$-ray diffraction (XRD) measurements were carried out Philips diffractometer (PW-1710). using a $\mathrm{CuK} \alpha(\lambda=1.54 \AA)$ radiation source accelerated at $40 \mathrm{KV}$ and $30 \mathrm{~mA}$ at room temperature. All scanning were performed in $2 \theta$ range 2-20 degrees with scan speed: $2 \mathrm{deg} / \mathrm{min}$.

The morphology of the samples surfaces were investigated using scanning electron microscopy (SEM) (JSM-5900 LV).

The specific BET surface area was measured at $77 \mathrm{~K}$ using liquid $\mathrm{N}_{2}$ adsorption (Micromeritics - TriStar 3020 Gas Adsorption Analyzer).

Thermal gravimetric analysis (TGA) was conducted on a Shimadzu TGA $-51 \mathrm{H}$ analyser with temperature program $=$ heat from $30{ }^{\circ} \mathrm{C}$ to $900{ }^{\circ} \mathrm{C}$; heating rate of $10^{\circ} \mathrm{C} / \mathrm{min}$ in Nitrogen atmosphere with a purge rate of $20 \mathrm{ml} / \mathrm{min}$.

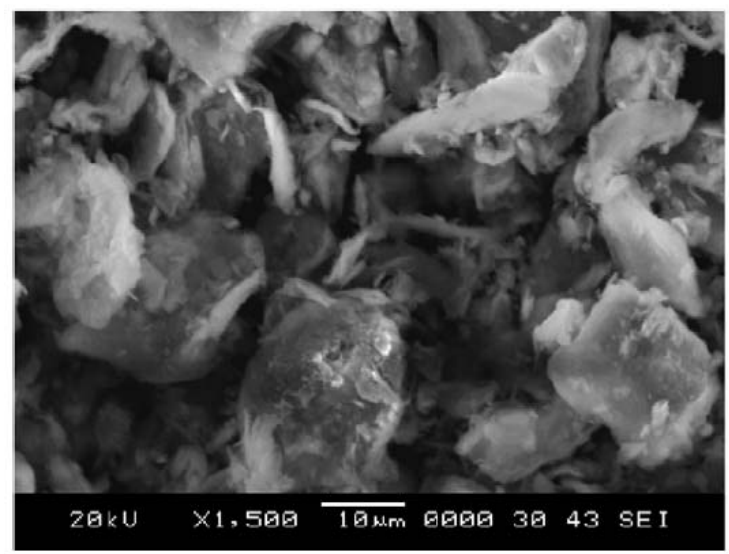

(a)

Fig. 2 - SEM micrographs of: (a) MMT (b) OMMT.
A UV-vis spectrophotometer 160 A Shimadzu was used for determining dye concentration.

\section{RESULTS AND DISCUSSION}

\section{Characterization of Sorbent}

\subsection{Scanning electron microscope images (SEM)}

The surface morphology of both, the MMT and the OMMT is illustrated in Fig. 2. This figure presents typical images of both kinds of clay, when they are examined with SEM. MMT shows a massive and aggregated morphology. However, the presence of the alkylammonium cation expands the clay structure, which exhibits a more open morphology, while individual blocks of layers can be distinguished in it (Fig. 2b).

\subsection{IR spectroscopy}

FTIR spectra of MMT and those OMMT are shown in Fig. 3. As noted, all the spectra show bands at 3636 and $3395 \mathrm{~cm}^{-1}$ attributed to $\mathrm{O}-\mathrm{H}$ stretching for the silicate and water, respectively, $1639 \mathrm{~cm}^{-1}$ (related to $\mathrm{O}-\mathrm{H}$ bending), $1040 \mathrm{~cm}^{-1}$ (owing of stretching vibration of $\mathrm{Si}-\mathrm{O}-\mathrm{Si}$ from silicate), $917 \mathrm{~cm}^{-1}$ (from Al-OH-Al deformation of aluminates), and 524 and $472 \mathrm{~cm}^{-1}$ (Al-O stretching and $\mathrm{Si}-\mathrm{O}$ bending vibrations of MMT, respectively). ${ }^{22}$ However, there are some bands in OMMT spectra which are not exhibited by the MMT; these bands were located at 2924, 2842 and $1475 \mathrm{~cm}^{-1}$ and were assigned to $\mathrm{C}-\mathrm{H}$ vibrations of methylene groups (asymmetric stretching, symmetric stretching and bending, respectively) from chemical structure of the surfactant. ${ }^{23}$

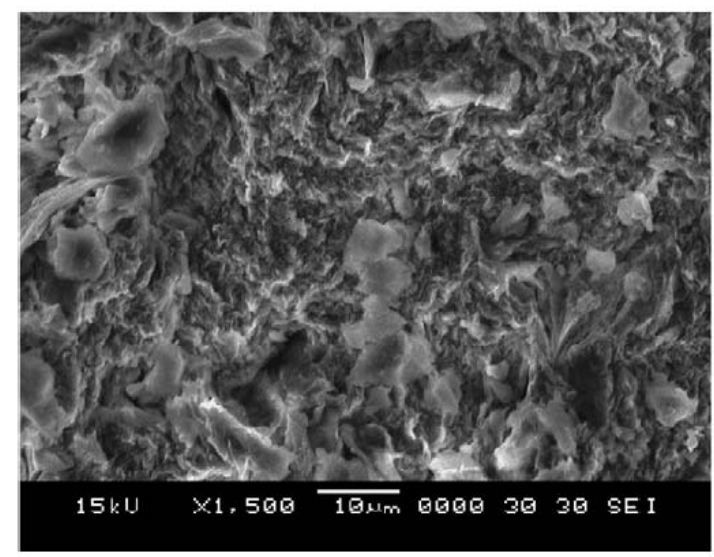

(b) 


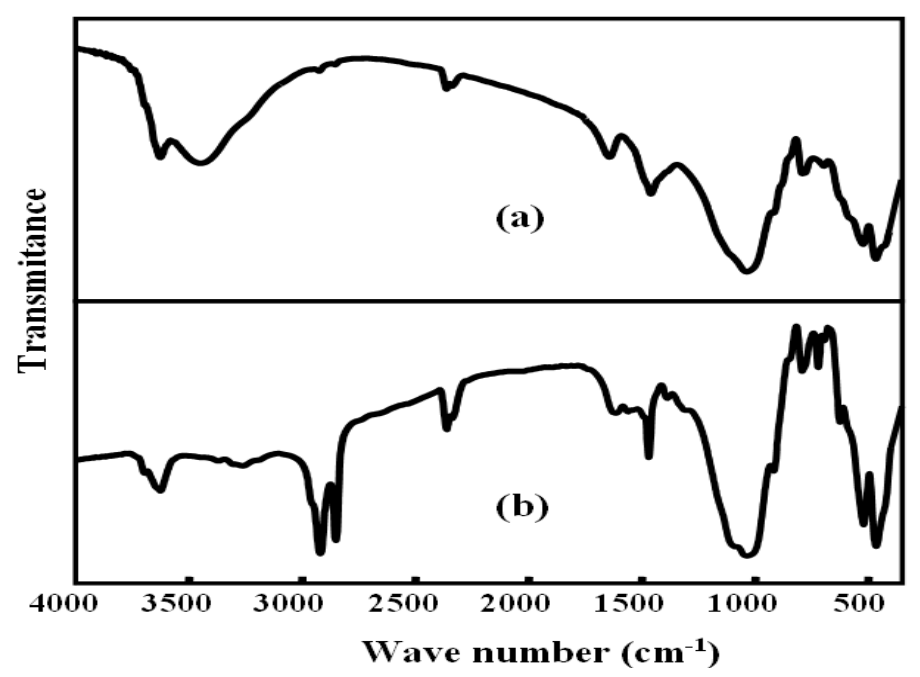

Fig. 3 - FTIR spectra of: a) MMT and b) OMMT.

\subsection{XRD analysis}

The X-ray spectra for powder MMT, and OMMT are shown in Fig. 4. Bragg's equation, $2 d$ $\sin \theta=n \lambda$, was used to calculate the basal spacing of the OMMT as well as the MMT.

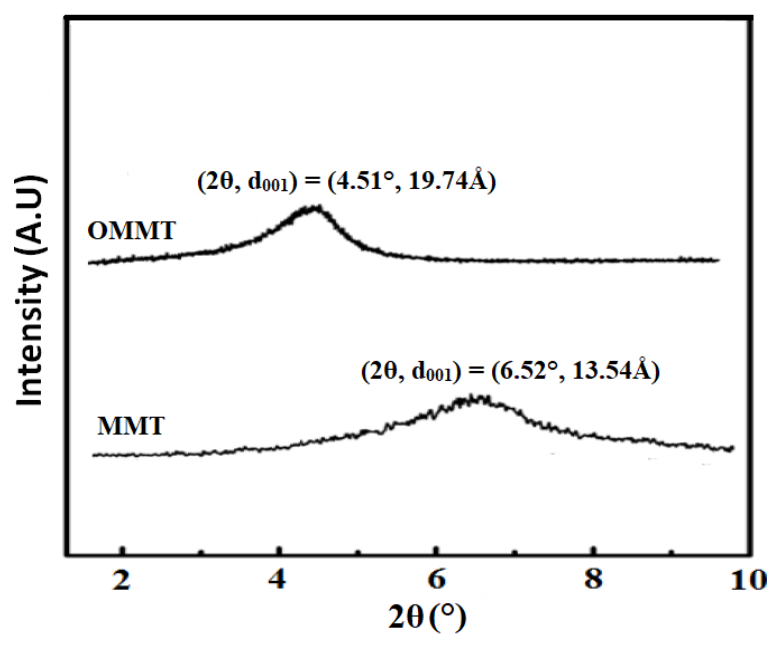

Fig. 4 - XRD pattern of MMT and OMMT.

The characteristic $d_{001}$ diffraction peak for MMT in the $2 \theta$ region is located at $6.52^{\circ}, d_{001}=13.54 \AA$. The modification of the MMT with HTACl shifts the $d_{001}$ peak to lower values in the $2 \theta$ region, which are located at $4.51^{\circ}, d_{001}=19.74 \AA$ for OMMT. This shift suggests an increase in the basal spacing of the silicate platelets. The increase of the basal spacing is due to the penetration and grafting of the quaternary salt via ion exchange to the clay platelets. The indexing of the $d_{001}$ peak in the diffraction patterns of modified clays also suggests that the morphology of the clays is intercalated. ${ }^{24}$

\subsection{Thermogravimetric analysis (TGA)}

The TGA curves MMT and OMMT are shown in Fig. 5. MMT displays two thermal degradation transitions. The first one occurs in the temperature range $100-350{ }^{\circ} \mathrm{C}$ and is due to the vaporization of both the free water (i.e., the water sorbed on the external surfaces of crystals) and the water residing inside the interlayer space, forming hydration spheres around the exchangeable cation. ${ }^{25}$ The second transition takes place at higher temperatures (between 500 and $800{ }^{\circ} \mathrm{C}$ ) and is owing to the structural water resulting from the dehydroxylation of clay $\mathrm{OH}$ units.

On the other hand, OMMT follows a fourstep decomposition process. The vaporization of free water takes place at temperatures below $200^{\circ} \mathrm{C}$, while the surfactant's decomposition happens in the temperature between $200-500^{\circ} \mathrm{C}$. Dehydroxylation of the aluminosilicates occurs between 500 and $800{ }^{\circ} \mathrm{C} .^{26}$

\subsection{BET}

The specific surface area and pore size distribution were determined by nitrogen adsorption isotherms for both MMT and OMMT were shown in Fig. 6. Both MMT and OMMT have mesoporous structures. Mesoporous structure was shown by a hysteresis between adsorption and desorption curve after relative pressure $\left(\mathrm{P} / \mathrm{P}_{0}\right)$ of 0.4 . The difference between MMT and OMMT lies on its volumetric adsorption capacity $\left(\mathrm{V}_{\mathrm{ads}}\right)$ and $\mathrm{BET}$ surface area. OMMT had larger Vads than MMT $\left(0.75 \mathrm{~cm}^{3} / \mathrm{g}\right.$ vs $\left.0.51 \mathrm{~cm}^{3} / \mathrm{g}\right)$ but lower surface area $\left(101 \mathrm{~m}^{2} / \mathrm{g}\right.$ vs $\left.119 \mathrm{~m}^{2} / \mathrm{g}\right)$ which indicates the formation of larger pore on OMMT as compared to MMT due to HTACl insertion MMT interlayer. 


\section{Adsorption studies}

\subsection{Effect of Contact Time}

The effect of contact time on removal of MB by MMT and OMMT is shown in Fig. 7. The dye adsorption by OMMT sorbent is faster than that of MMT. The rate of adsorption is initially quite rapid, with most of the compound being adsorbed within the first few minutes. The rate of adsorption then slows down with the elapsed time until an apparent equilibrium is reached. As seen from Fig. 7, that equilibrium time required for the adsorption of $\mathrm{MB}$ is almost $60 \mathrm{~min}$. HTACl modification covered the MMT surfaces and increased molecular interaction between MB molecules. Therefore, uptake of dyes increased from bentonite to OMMT. After the equilibrium time, the increasing rate of adsorption of dye decreased and the amount of dye adsorbed remained almost the same. The removal of $\mathrm{MB}$ from aqueous solutions by modified montmorillonite seems to be more effective than in the unmodified sample.

The UV spectra of MB and MB loaded OMMT was studied. The spectrum is show in Fig. 8, which shows that there is a major absorbance peak at 663 $\mathrm{nm}$ in the visible spectra of MB. This absorbance peak decreased in intensity as treatment time increased, and after treatment for $240 \mathrm{~min}$ this peak almost totally disappeared, which indicates the dye diminished after adsorption. (a)

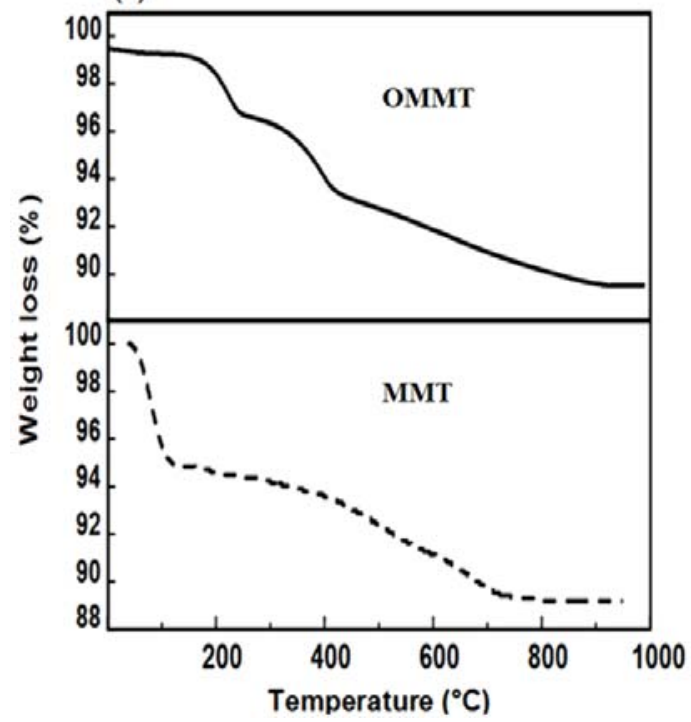

(b)

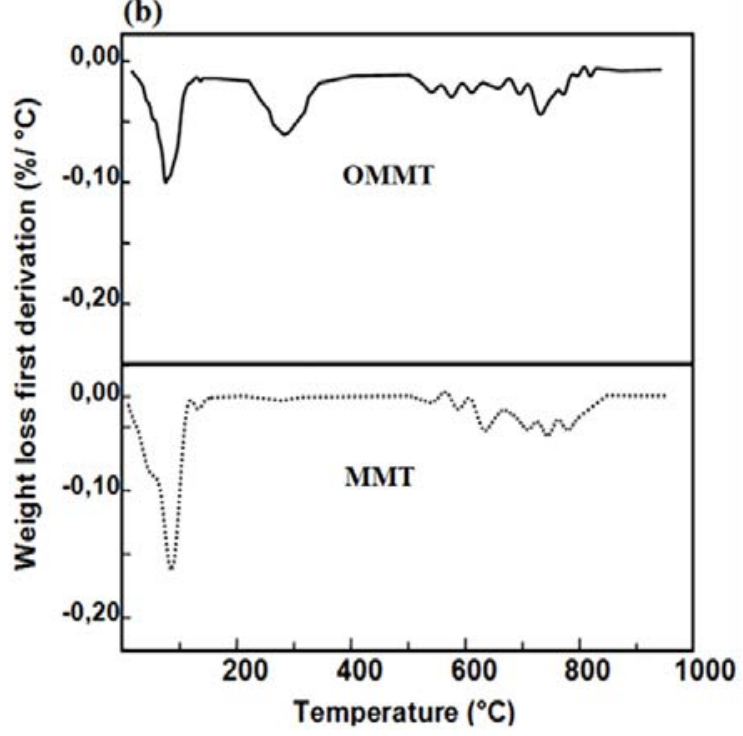

Fig. 5 - TGA (a) and DTGA (b) curves of: MMT and OMMT.

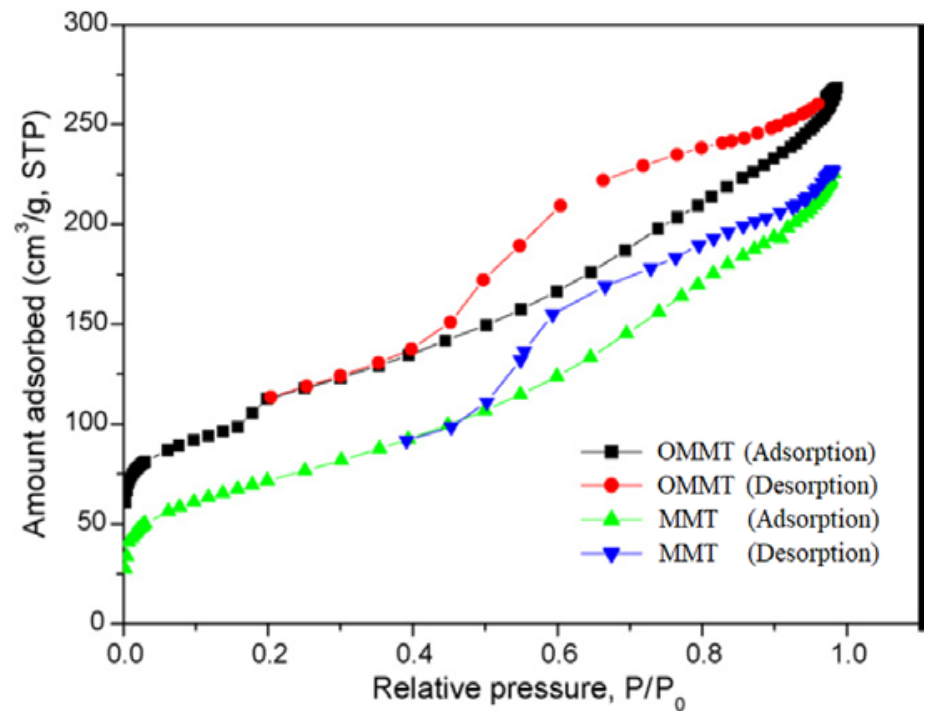

Fig. 6 - Nitrogen adsorption/desorption isotherms MMT and OMMT at 77K. 


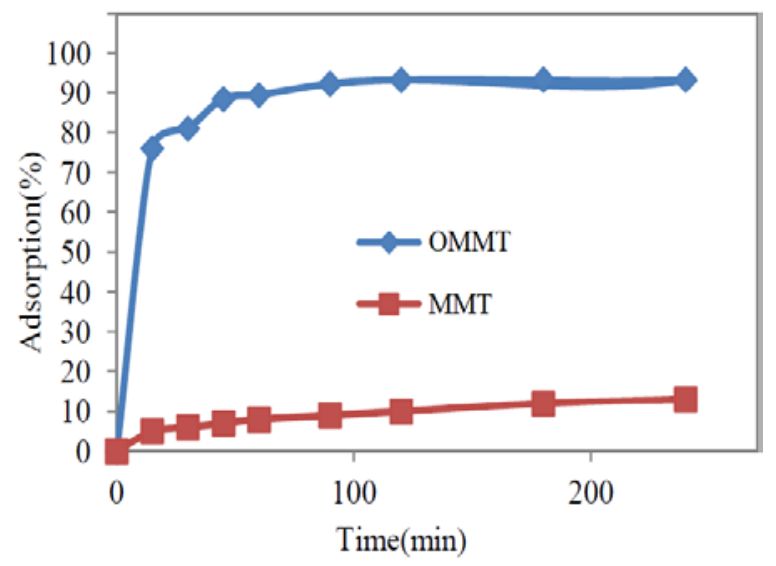

Fig. 7 - Effect of contact time on the sorption of MB. (50 ml of $100 \mathrm{mg} / \mathrm{L}$ of MB, $\mathrm{pH} 12,0.5 \mathrm{~g}$ sorbent at room temperature).

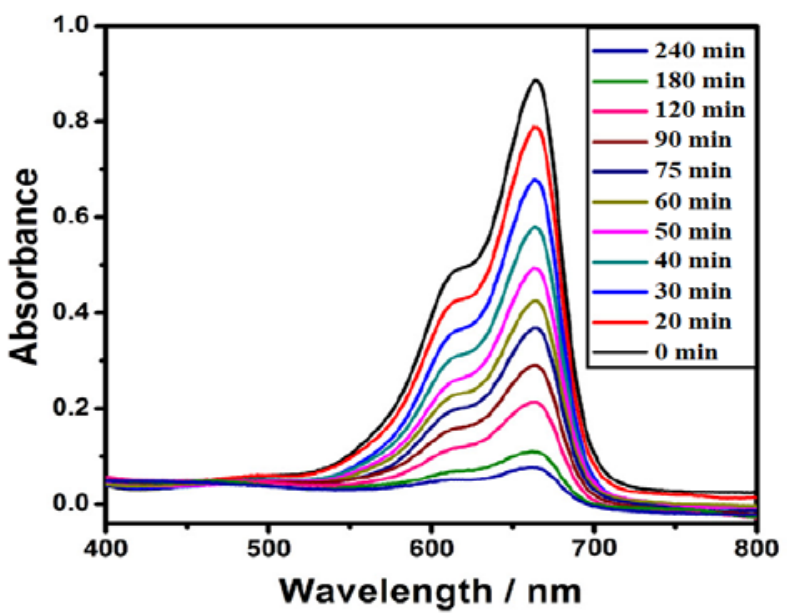

Fig. 8 - UV-Vis electronic spectra of MB before and after adsorption at different times $(50 \mathrm{ml} \mathrm{MB}$ solution, initial concentration $100 \mathrm{mg} / \mathrm{L}$, initial $\mathrm{pH}$ 12, $0.1 \mathrm{~g}$ adsorbent OMMT).

\section{2. Effect of $\mathrm{pH}$}

The effect of $\mathrm{pH}$ on adsorption of $\mathrm{MB}$ on OMMT was studied by varying the $\mathrm{pH}$ of solution from 2 to 12 . The experiments were carried out for $50 \mathrm{ml}$ of dye $100 \mathrm{mg} / \mathrm{L}$ and $0.5 \mathrm{~g}$ of sorbents for 60 min contact time. It was observed that $\mathrm{pH}$ gives a significant influence to the adsorption process. ${ }^{27,28}$ The adsorption percentage of MB with OMMT is increased with increasing $\mathrm{pH}$ value, and the maximum uptake of the dyes takes place at around $\mathrm{pH} 12$ (Fig. 9). Adsorption of MB at higher $\mathrm{pH}$ is higher and it may be explained on the assumption that $\mathrm{HTACl}$ modification covered the clay surfaces with positive charges and increased electrochemical interaction between dye molecules and modified clay surfaces. The high Adsorption capacity is due to the strong electrostatic interaction between $\mathrm{CH}_{3}-\left(\mathrm{CH}_{2}\right)_{15}-\mathrm{N}^{+}\left(\mathrm{CH}_{3}\right)_{3}$ of OMMT and MB. In contrast, betonite contains fewer adsorption sites, so a lower adsorption capacity was obtained due to the lack of electrostatic interaction between dye and bentonite. ${ }^{29}$ Therefore, it is observed that the rate of removal of dyes increases with increased in $\mathrm{pH}$ for bentonite remaining constant and the percentage of dye removal is very low.

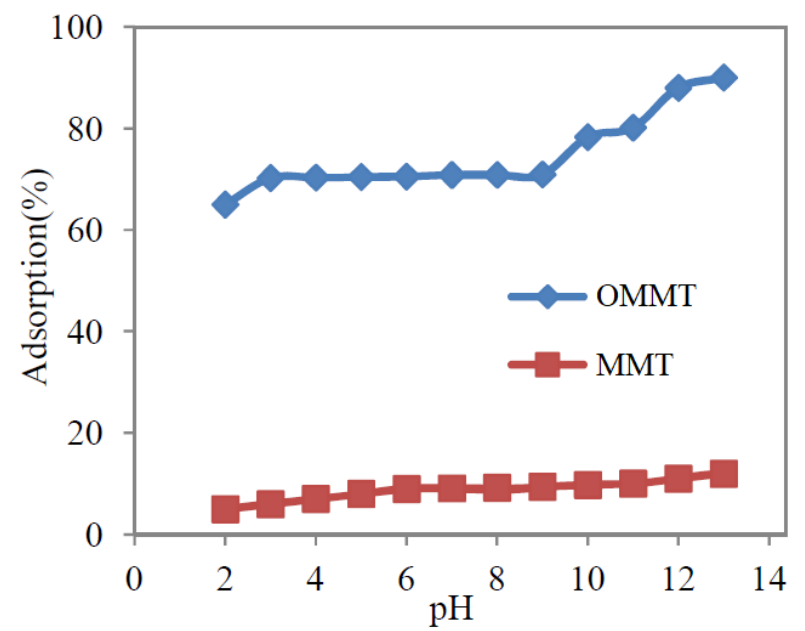

Fig. 9 - Effect of $\mathrm{pH}$ for adsorption MB onto MMT and OMMT $(50 \mathrm{ml}$ of $100 \mathrm{mg} / \mathrm{L}$ of $\mathrm{MB}$ and $0.5 \mathrm{~g}$ sorbent at room temperature).

\subsection{Effect of Initial Dye Concentration}

The adsorption experiments were carried out in the concentration range of dye from $10-70 \mathrm{mg} / \mathrm{L}$ at $0.5 \mathrm{~g}$ sorbent, contact time $60 \mathrm{~min}$, and $\mathrm{pH} 12$. As shown in Fig. 10, when the initial dye concentration was increased to $15 \mathrm{mg} / \mathrm{L}$, the adsorption uptake of dye increased to $94 \%$ for $\mathrm{MB}$, and at higher concentration the uptake is constant. These indicate that the initial dye concentrations play an important role in the adsorption of $\mathrm{MB}$ on the OMMT. $^{30}$

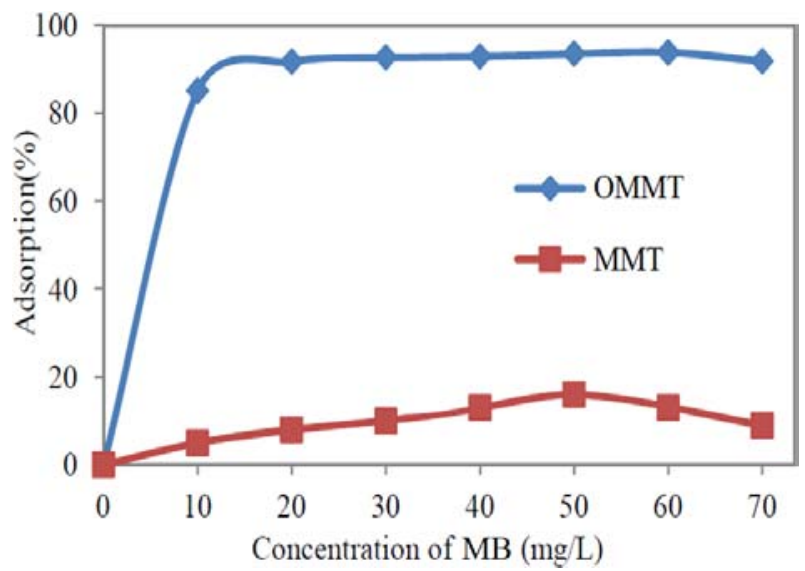

Fig. 10 - Effect of dye concentration for adsorption MB onto MMT and OMMT $(50 \mathrm{ml}$ of MB and $0.5 \mathrm{~g}$ sorbent at room temperature). 


\subsection{Effect of Adsorbent Dose}

The effect of the adsorbent dose on the removal of MB was studied by varying the amount of adsorbent OMMT. Fig. 11 shows the removal of MB by MMT and OMMT at different adsorbent doses $(0.1-1 \mathrm{~g})$ for the volume of $50 \mathrm{~mL}$ at dye concentration $100 \mathrm{mg} / \mathrm{L}$. The results, in Fig.11, clearly show an increase in adsorption with increases in the amount of adsorbents. An increase in adsorption with the adsorbent dosage can be attributed to the availability of more adsorption sites and greater surface area for contact. At $\mathrm{m}>0.2 \mathrm{~g}$, the incremental $\mathrm{MB}$ uptake is very small as the MB surface concentration and the MB bulk solution concentration come to equilibrium with each other. ${ }^{31,32}$

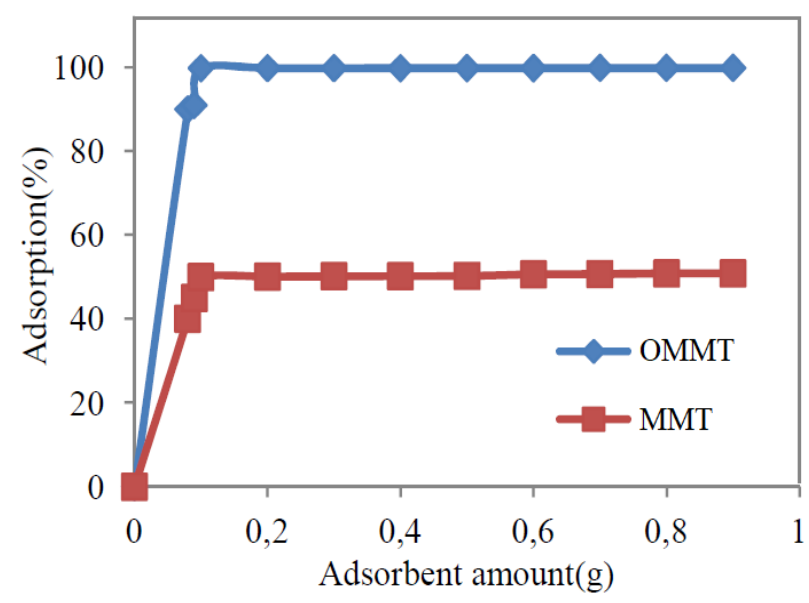

Fig. 11 - Effect of amount of OMMT and MMT on the adsorption of MB.

\subsection{Adsorption Kinetics}

It is important to be able to predict the rate at which contamination is removed from the aqueous solution in order to design an adsorption treatment plant. The transient behavior of the dye adsorption process was analyzed using the pseudo-first and pseudo-second kinetic models. The pseudo-firstorder kinetic model was appropriate for lower concentration, with the equation expressed as follows: ${ }^{33}$

$$
\ln \left(q_{e}-q_{t}\right)=\ln q_{e}-k_{1} t
$$

The rate of pseudo-second-order reaction depends on the amount of adsorbed solution, the surface of adsorbent, and the amount of adsorption at the equilibrium. The model was represented in the following linear form: ${ }^{34,35}$

$$
\frac{t}{q_{t}}=\frac{1}{k_{2} q_{e}^{2}}+\frac{1}{q_{e}} t
$$

where $q_{t}$ is the amount of dye adsorbed at time $\mathrm{t}$ $(\mathrm{mg} / \mathrm{g}), q_{e}$ is the adsorption capacity at equilibrium $(\mathrm{mg} / \mathrm{g})$, and $k_{1}$ and $k_{2}$ are the apparent rate constants.

During this study, the two adsorption kinetic pseudo-first- and second-order models were used. The kinetics of pseudo-first- and second-order are discussed in Figs. 12 and 13.

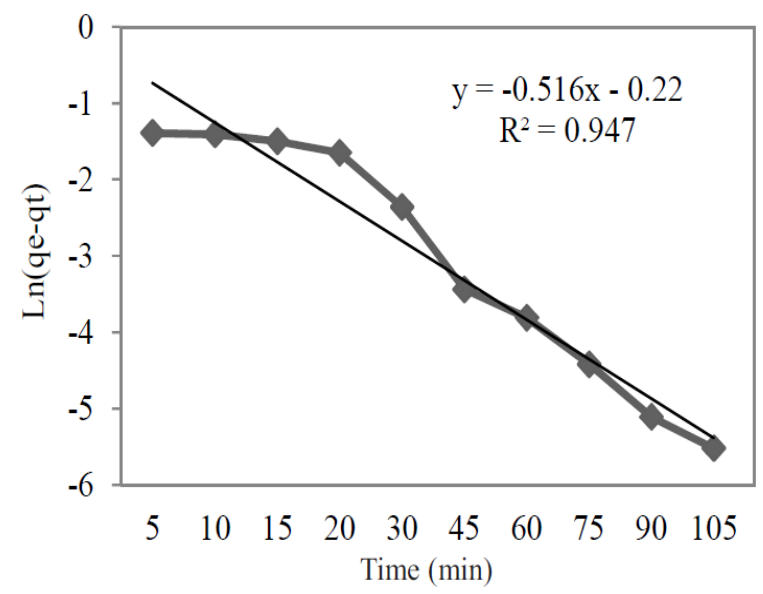

Fig. 12 - Kinetic of pseudo-first-order model for adsorption of MB onto OMMT. (50 ml of initial concentration $100 \mathrm{mg} / \mathrm{L}$, $\mathrm{pH} 12,0.5 \mathrm{~g}$ adsorbent).

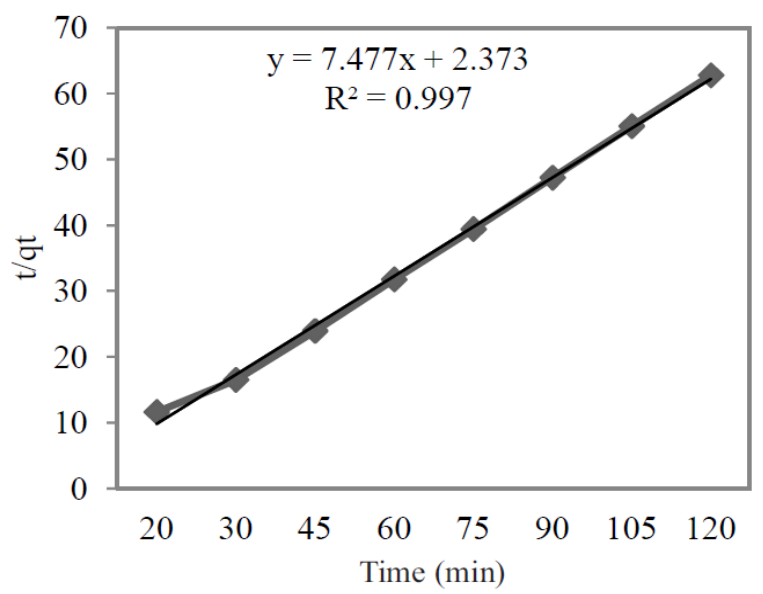

Fig. 13 - Kinetic of pseudo-second-order model for adsorption of MB onto OMMT. (Initial concentration $100 \mathrm{mg} / \mathrm{L}$, pH 12, $0.5 \mathrm{~g}$ adsorbent).

The related parameters are shown in Table 1. As shown, the $\mathrm{R}^{2}$ value of the pseudo-second-order model is better fitted and the adsorption process follows pseudo-second older kinetics.

\subsection{Adsorption Isotherm of MB}

The adsorption isotherm indicates how the adsorption molecules are distributed between the liquid phase and the solid phase when the adsorption process reaches an equilibrium state. 
Table 1

Kinetics parameters for the removal of MB

\begin{tabular}{c|c|c|c}
\hline \multicolumn{2}{c|}{ First order } & \multicolumn{2}{c}{ Second order } \\
\hline $\mathrm{R}^{2}$ & $k_{1}$ & $\mathrm{R}^{2}$ & $k_{2}$ \\
\hline 0.947 & 0.516 & 0.997 & 0.40 \\
\hline
\end{tabular}

The Langmuir ${ }^{36}$ adsorption model is given as:

$$
\frac{q_{e}}{q_{\max }}=\frac{K_{L} \times C_{e}}{\left(1+K_{L} \times C_{e}\right)}
$$

The linearized form of Langmuir can be written as follows:

$$
\frac{C_{e}}{q_{e}}=\frac{1}{\left(q_{\max } \times K_{L}\right)}+\frac{C_{e}}{q_{\max }}
$$

where $q_{e}$ is the solid-phase equilibrium concentration $(\mathrm{mg} / \mathrm{g}), \mathrm{Ce}$ is the liquid equilibrium concentration of dye in solution $(\mathrm{mg} / \mathrm{L}), K_{L}$ is the equilibrium adsorption constant related to the affinity of binding sites $(\mathrm{mg} / \mathrm{L})$, and $q_{\max }$ is the maximum amount of dye per unit weight of adsorbent for complete monolayer coverage $(\mathrm{mg} / \mathrm{g})$.

The Freundlich ${ }^{37}$ adsorption isotherm model, which is an empirical equation used to describe heterogeneous adsorption systems, can be represented as follows:

$$
q_{e}=K_{F} \times C_{e}^{1 / n_{F}}
$$

where $q_{e}$ and $C e$ are defined as above, $K_{F}$ is the Freundlich constant representing the adsorption capacity $(\mathrm{mg} / \mathrm{g})$, and $n$ is the heterogeneity factor depicting the adsorption intensity. In most references, Freundlich adsorption Eq. (7) may also be expressed as Eq. (8):

$$
\log q_{e}=\log K_{F}+\frac{1}{n_{F}} \log C_{e}
$$

The adsorption of $\mathrm{MB}$ was performed by shaking $0.5 \mathrm{~g}$ of sorbent in $50 \mathrm{~mL} \mathrm{MB}$ at $30{ }^{\circ} \mathrm{C}$ and $\mathrm{pH}$ 12. It is known that the Langmuir isotherm is used on the supposition that the surface of the adsorbent is a homogenous surface, whereas the
Freundlich isotherm applies to the adsorption process on a heterogeneous surface. The isotherm parameters of Langmuir and Freundlich for adsorption of MB onto OMMT from graphs of equations 6 and 8 are shown in Table 2. A value for $1 / n$ below one indicates a normal Langmuir isotherm, while $1 / n$ above one is indicative of cooperative adsorption. As seen from Table 2, the Langmuir model yields a somewhat better fit $\mathrm{R}^{2}$ than the Freundlich model. The values of $1 / \mathrm{n}$ between $0.162-0.244$ indicate favorable adsorption. ${ }^{38,39}$

\subsection{Thermodynamic Parameters}

In any adsorption process, entropy consideration must be taken into account in order to determine what process will occur spontaneously. Values of thermodynamic parameters are the actual indicators for practical application of a process. The amount of dye adsorbed at equilibrium at different temperatures $\left(20,30,40\right.$, and $\left.50^{\circ} \mathrm{C}\right)$ have been examined to obtain thermodynamic parameters for the adsorption system. The thermodynamic parameters, change in the standard free energy $\left(\Delta \mathrm{G}^{\circ}\right)$, enthalpy $\left(\Delta \mathrm{H}^{\circ}\right)$, and entropy $\left(\Delta \mathrm{S}^{\circ}\right)$ associated with the adsorption process and these were determined using the following equations $:^{40}$

$$
\Delta G^{\circ}=-R T \ln K_{c}
$$

where, $\Delta \mathrm{G}^{\circ}$ is the standard free energy change, $R$ the universal gas constant $(8.314 \mathrm{~J} / \mathrm{mol} . \mathrm{K}), \mathrm{T}$ the absolute temperature, and $\mathrm{KC}$ the equilibrium constant. The apparent equilibrium constant of sorption $K C$ is obtained from:

$$
K_{C}=\frac{C_{A}}{C_{S}}
$$

Table 2

Langmuir and Freundlich constants for the adsorption of MB onto OMMT

\begin{tabular}{c|c|c|c|c|c|c}
\hline \multicolumn{3}{|c|}{ Freundlich } & \multicolumn{3}{c}{ Langmuir } \\
\hline $\mathbf{R}^{\mathbf{2}}$ & $\mathbf{1} / \boldsymbol{n}$ & $\boldsymbol{K} \boldsymbol{f}$ & $\mathbf{R}^{\mathbf{2}}$ & $\boldsymbol{K L} \mathbf{( L / m g})$ & $\boldsymbol{q}_{\boldsymbol{m}}(\mathbf{m g} / \mathbf{g})$ & Temperature $\left({ }^{\circ} \mathbf{C}\right)$ \\
\hline 0.953 & 0.245 & 7.879 & 0.995 & 0.151 & 18.95 & 20 \\
0.984 & 0.164 & 9.641 & 0.997 & 0.162 & 19.96 & 30 \\
0.977 & 0.176 & 8.668 & 0.983 & 0.156 & 17.57 & 40 \\
0.983 & 0.180 & 6.681 & 0.985 & 0.145 & 16.33 & 50 \\
0.987 & 0.201 & 6.622 & 0.992 & 0.132 & 15.36 & 60 \\
\hline
\end{tabular}


where $\mathrm{KC}$ is the equilibrium constant, $\mathrm{CA}$ is the amount of dye adsorbed on the adsorbent of solution at equilibrium $(\mathrm{mg} / \mathrm{L}), \quad \mathrm{CS}$ is the equilibrium concentration of dye in the solution $(\mathrm{mg} / \mathrm{L}) . \mathrm{KC}$ values were calculated at different temperature to allow the determination of the thermodynamic equilibrium constant $(\mathrm{KC}){ }^{40,41}$ The free energy changes also are calculated by using the following equation:

$$
\ln K_{C}=-\frac{\Delta G^{\circ}}{\mathrm{RT}}=-\frac{\Delta H^{\circ}}{R T}+\frac{\Delta S^{\circ}}{R}
$$

$\Delta \mathrm{H}^{\circ}$ and $\Delta \mathrm{S}^{\circ}$ calculate the slope and intercept of van't Hoff plots of $\ln \mathrm{KC}$ versus $1 / \mathrm{T}$ (Fig. 14). The results of thermodynamic parameters of $\mathrm{MB}$ adsorption onto OMMT are given in Table 3 . The positive $\Delta \mathrm{H}^{\circ}$ value obtained in Table 3 indicates that the process is endothermic in nature. The overall standard free energy change during the adsorption process was negative for the experimental range of temperatures corresponding to a spontaneous physical process of $\mathrm{MB}$ adsorption, and the system did not gain energy from an external source. It becomes more favorable with increased temperature. ${ }^{41}$

\subsection{Activity comparison of OMMT with reported adsorbents}

Table 4 summarizes a comparative evaluation of the adsorption capacities for MB onto different adsorbents. The adsorbent prepared in this work showed relatively high adsorption capacity for MB of $19.96 \mathrm{mg} / \mathrm{g}$, as compared to some previous works as reported in the literature.

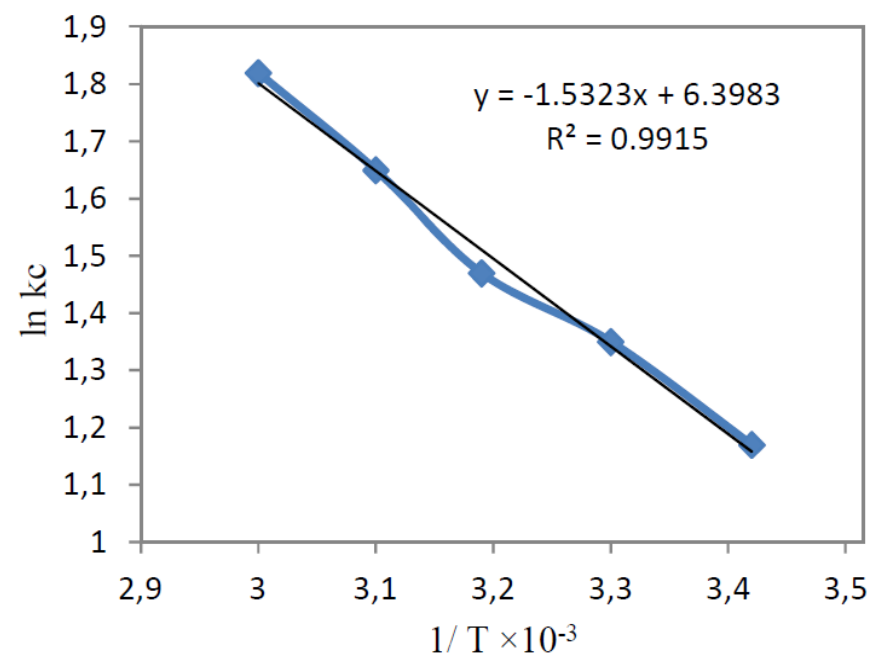

Fig. 14 - Plot of $\ln$ Kc verses 1/T for adsorption MB onto OMMT.

Table 3

Thermodynamic parameters for adsorption of MB onto OMMT

\begin{tabular}{c|c|c|c|c}
\hline $\left.\boldsymbol{\Delta} \mathbf{S}^{\circ} \mathbf{( K J} / \mathbf{m o l} . \mathbf{K}\right)$ & $\left.\boldsymbol{\Delta} \mathbf{H}^{\circ} \mathbf{( J / m o l}\right)$ & $\left.\boldsymbol{\Delta G}^{\circ} \mathbf{( K J} / \mathbf{m o l}\right)$ & $\mathbf{K C}$ & $\mathbf{T} \mathbf{( K )}$ \\
\hline \multirow{3}{*}{53.18} & & -2.83 & 3.21 & 293 \\
& \multirow{3}{*}{12.72} & -3.38 & 3.84 & 303 \\
& & -3.74 & 4.23 & 313 \\
& & -4.41 & 5.19 & 323 \\
& & -5.55 & 7.47 & 333 \\
\hline
\end{tabular}

Table 4

Comparison of adsorption capacities of $\mathrm{MB}$ onto different adsorbents

\begin{tabular}{l|c|c}
\hline Adsorbent & $\mathbf{q}_{\max }(\mathbf{m g} / \mathbf{g})$ & References \\
\hline Fly ash & 10.20 & 42 \\
Wheat shells & 16.56 & 43 \\
Tamarindfruitshell & 1.72 & 44 \\
Raw beech sawdust & 9.78 & 45 \\
TSAC & 13.27 & 46 \\
Activated rice husks & 0.21 & 47 \\
OMMT & 19.96 & Present work \\
\hline
\end{tabular}




\section{CONCLUSIONS}

The adsorption of MB from aqueous solution using OMMT was investigated under different experimental conditions in batch process. Results show that the adsorption capacity increases with the increase of contact time, initial $\mathrm{MB}$ concentration, adsorbent dosage and $\mathrm{pH}$ in the range of 2-12, where ionization surface area. The adsorption of MB onto the OMMT reached equilibrium within about $60 \mathrm{~min}$. The Langmuir adsorption isotherm was found to have the best fit to the experimental data. The adsorption kinetics can be predicted by pseudo-second-order kinetics. Adsorption of MB onto OMMT is determined as an endothermic process and spontaneous, due to the negative sign of its standard free energy, indicating physisorption as the controlling step of adsorption. The results indicate that OMMT could be used in potential applications as economical and environmentally friendly substrate, as they are effective adsorbents to removal methylene blue dye from aqueous solutions under soft conditions.

\section{REFERENCES}

1. E. F. Kankeu, H. Mittal, S.B. Mishra and A.K. Mishra, J. Ind. Engineer. Chem., 2015, 22, 171-178.

2. A. A. Adeymo, I. O. Adeoye and O. S. Bello, Appl. Water Sci., 2017, 7, 543-568.

3. T. Seow and W. Lim, Inter. Appl. Eng. Res., 2016, 11, 2675-2679.

4. J. Ghobadi, M. Arami and H. Bahrami, J. Color Sci. Technol., 2013, 7, 103-112.

5. S. Dawood and T.K. Sen., Water Res., 2012, 46, 1933-46.

6. M. Kharub, J. Environ. Research Development, 2012, 6 , 879-883.

7. K. D. Belaid, S. Kacha, M. Kameche and Z. Derriche, J. Environ. Chem. Eng., 2013, 1, 496-503.

8. S. Kara, C. Aydiner, E. Demirbas, M. Kobya and N. Dizge, Desalination, 2007, 212, 282-293.

9. S. Wang and E. Ariyanto, J. Colloid. Interface Sci., 2007, 314, 25-31.

10. A. Tor and Y. Cengeloglu, J. Hazard. Mater., 2006, 138, 409-415.

11. C. Namasivayam and D. Kavitha, Dyes Pigm., 2002, 54, 47-58.

12. D. Shen, J. Fan, W. Zhou, B. Gao, Q. Yue and Q. Kang, J. Hazard. Mater., 2009, 172, 99-107.

13. F. Ayari, E. Srasra and M. T. Ayadi, Desalination, 2007, 206, 499-506.

14. A. A. Adeymo, I. O. Adeoye and O. S. Bello, Appl. Water Sci. 2017, 7, 543-568.

15. E. Bulut, M. Ozacar and I. A. Sengil, J. Hazard Mater, 2008, 154, 613- 622 .
16. E. P. Ortegaa and R. L. Ramos, Chem. Eng. J., 2013, 225, 535-546.

17. T. W. Seow and C. K. Lim, Inter. Appl. Eng. Res. 2016, $11,2675-2679$.

18. A. R. Obiageli, J. Chem. Technol. Metallur., 2017, 52, 491-504.

19. D. C. D. Santos, M. A. Adebayo and E. C. Limaetal, J. Brazilian Chem. Soc., 2015, 26, 924-938.

20. J. N. Putro, S. P. Santoso, S. Ismadji and Y. H. Ju, Microporous Mesoporous Mater., 2017, 246, 166-177.

21. S. Boudjemaa, Rev. Roum. Chim., 2019, 64, 35-44.

22. M. S. Lakshmi, B. Narmadha and B. S. R. Reddy, Polym. Degrad. Stab., 2008, 93, 201-213.

23. A. A. Adeyemo, I. O. Adeoye and O. S. Bello, Appl. Water Science, 2017, 7, 543-568.

24. S. Boudjemaaa and B. Djellouli, Russ. J. Appl. Chem., 2014, 87, 1464-1473.

25. Y. C. Lee, E. J. Kim, D. A. Ko and J. W. Yang, J. Hazard. Mater. 2011, 196, 101-108.

26. A. Salem and L. Karimi, Korean J. Chem. Engineer., 2009, 26, 980-984.

27. M. Aliu, L. P. Beqiri and S. Kadriuetal, 2016, 11, 409413.

28. M. Toor and B. Jin, Chem. Eng. J., 2012, 187, 79-88.

29. M. Jiang, X. Jin, X. Lu and Z. Chen, Desalination, 2010, 252, 33-39.

30. Z. Cheng, L. Zhang, X. Guo, X. Jiang and T. Li, Spectrochim. Acta Part A: Molec. Biomolec. Spectroscopy, 2015, 137, 1126-1143.

31. U. F. Alkaram, A. A. Mukhlis and A. H. Al-Dujaili, J. Hazard. Mater., 2009, 169, 324-332.

32. L. Akinola and A. Umar, J. Appl. Sci. Environ. Management, 2015, 19, 279-288.

33. G. Crini and E. Lichtfouse, Environ. Chem. Lett., 2018, $17,145-155$

34. S. Al-Shahrani, Alexandria Engineer. J., 2014, 53, 205211.

35. K. Al-Essa, Sci. J. Chem., 2018, 6, 1-10.

36. H. Freundlich, Phys. Chem. Soc., 1906, 40, 1361-1368.

37. I. Langmuir, J. Am. Chem. Soc., 1918, 40, 1361-1403.

38. E. Pehlivan and G. Arslan, Fuel Process. Technol., 2007, $88,99-106$.

39. H. Chen and J. Zhao, Adsorption, 2009, 15, 381-389.

40. H. H. A. Ghafar, T. Salem, E. K. Radwan, A. A. ElSayed, M. A. Embaby and M. Salama, Egyptian J. Chem., 2017, 60, 395-406.

41. E.G. Sogut and N. Caliskan, Fresenius Environ. Bull., 2017, 26, 2720-2728.

42. Q. Liu, Y. M. Zhou, L. Q. Zou, T. Deng, J. Zhang, Y. Sun, X. X. Ruan, P. Zhu and G. R. Qian, Desalin. Water Treat., 2011, 32, 179-186.

43. Y. Bulut and H. Aydın, Desalination, 2006, 194, 259267.

44. B. H. Hameed, A. T. M. Din and A. L. Ahmad, J. Hazard. Mater., 2007, 141, 819-825.

45. F. A. Batzias and D. K. Sidiras, J. Hazard. Mater. 2004, 114, 167-174.

46. S. Wong, N. A. N. Yaccob, N. Ngadi, O. Hassan and I. M. Inuwa, Chin. J. Chem. Eng., 2017, 26, 870-878.

47. V. K. Gupta, A. Mittal, R. Jain, M. Mathur and S. Sikarwar, J. Colloid Interf. Sci., 2006, 303, 80-86. 